\title{
Analysis of the third-grade curriculum for health subjects: Application of Health Education Curriculum Analysis Tool
}

This article was published in the following Dove Press journal: Journal of Multidisciplinary Healthcare

\author{
Leila Savari' \\ Maryam Shafiei ${ }^{2}$ \\ Hamid AllahverdiPour' \\ Hossein Matlabi' \\ 'Department of Health Education \\ and Promotion, Faculty of Health \\ Sciences, Tabriz University of Medical \\ Sciences, Tabriz, Iran; ${ }^{2}$ Department \\ of Educational Planning and \\ Administration, Shiraz University, \\ Shiraz, Iran
}

Purpose: Applying the Health Education Curriculum Analysis Tool (HECAT), the third-grade curriculum was assessed in accordance with health-related items.

Methods: A multimethod research was used to investigate the student textbooks and three modules including healthy eating, physical activity, and safety. Based on purposive sampling, curriculum committees were made up of teachers, elementary school principals, members of the parents-teachers' associations, and health care experts.

Results: Data obtained from the group discussion were analyzed based on the conventional content analysis approach. All modules received coverage percentages of $<34 \%$. The highest mean coverage percentage belonged to the safety module $(25.59 \%)$ and the lowest to healthy eating $(12.78 \%)$.

Conclusion: Suggested solutions were classified based on three general themes such as clarifying and determining healthy dietary behaviors and actions, educating life skills and adopting healthy diet behaviors, and finally utilizing social norms for adopting with healthy diet patterns. Keywords: module, safety, physical activity, Iran, health education, HECAT, primary schools, safety module, healthy eating

\section{Introduction}

Education as a prerequisite for health has been emphasized by the World Health Organization. ${ }^{1}$ Health-promoting schools pay attention to comprehensive health programs along with involving parents and societies. ${ }^{2}$ In a few studies, the school's role in obtaining education and related health has been mentioned. In order to maintain and improve health, schools make use of facilities, qualified staff, and an efficient system, which is one of the universal and desirable procedures for achieving this objective. ${ }^{3}$

Students spend 5 days of the week in school. Thus, schools could have an effective role in a child's health. In health-centered schools, along with scientific skills, cultural expectations and effective social skills on health behaviors are also taught. ${ }^{4}$ Health education is an inseparable part of three education programs for all students. School curricula must contain health-centered knowledge, attitude, and skills. ${ }^{5}$

Assessing the status of health education in elementary curricula and analyzing the content of health knowledge indicated that further attention to the aspects of health education is essential. Also, in a few of these curricula, enough consideration has been given to some of the aspects of health knowledge. ${ }^{6,7}$ In the current educational system of Iran, books are the most important educational tool. Thus, evaluating the concept of student textbooks for determining their strength and weaknesses is essential. ${ }^{8}$
Correspondence: Hossein Matlabi Faculty of Health Sciences, Attare Neishabouri St, Tabriz, Postal Code 51656658 II, Iran

Tel +989141008927

Fax +984I3334 473I

Emailhm1349@gmail.com 
The results of several studies about the content and textbooks revealed that some of the important health issues such as nutrition, oral health, and preventing high-risk behaviors have not been significantly considered, and the capacity for exhibiting health messages has not been completely used. Also, most of the courses were about personal hygiene, and the least courses were for preventing high-risk behaviors. ${ }^{9-11}$

In this regard, the Centers for Disease Control and Prevention introduced Health Education Curriculum Analysis Tool (HECAT). This tool strengthens schools' reasons for choosing educational programs and expanding health, so they can improve health knowledge, skills, and health behaviors according to student's needs and interests. ${ }^{12}$

The HECAT was designed based on accurate pieces of research evidence and is in accordance with the health education standards. These features allow curricula to be evaluated at all levels of education. The HECAT is a comprehensive set of health subjects including modules related to alcohol, tobacco, drugs, healthy diet, mental health, personal hygiene and physical health, immunity, sexual hygiene, and preventing violence, which are assessed and evaluated in different curricula. ${ }^{12}$

In regard to evaluating the instructions of preventing diseases and sexual health, the Washington State Department of Health reported that some programs focus on communications and social skills development. However, other scholars emphasize specific information such as sexual infectious diseases rather than personal relationships and skills. Furthermore, there are not enough experiences in this field, and the curriculum has not been evaluated systematically. ${ }^{13}$

Although in Iran the process of programming and compilation of student textbooks has a long history, health and prevention has a small share in the school syllabus, and evaluating programs and educational materials is new. ${ }^{6} \mathrm{In}$ other words, the reforms have been merely accomplished by incomplete evaluations, usually done after the completion of the program. Little or no time is allocated to teaching life skills, cultivating healthy habits and self-care, or helping change unhealthy lifestyles. ${ }^{14}$ Therefore, this study aimed to evaluate the third-grade curriculum in accordance with health-related items using the HECAT.

\section{Methods}

\section{Study design}

Based on the multimethod approach, this study was performed in three phases.

\section{HECAT committee and sampling}

According to purposive sampling and inclusion criteria, 21 recognized experts including well-informed teachers, principals of elementary schools, members of parent and teacher's foundation, district managers, health educators, and community health workers were recruited as members of the HECAT committee.

\section{Inclusion criteria}

In regard to the members of the parent and teacher's foundation, the inclusion criteria were being familiar with the general educational system and having academic education. Regarding the other experts, eligible participants had at least 5 years' experience and activity history.

\section{HECAT}

\section{Standards and frameworks}

The National Health Education Standards defines the essential knowledge and skills that every student should know and be able to do following the completion of a high-quality instructional program in health education (Table 1). These standards provide a foundation for curriculum development, instructional delivery, and assessment of student knowledge and skills in health education, for students in grades pre- $\mathrm{K}$ to 12 .

\section{General instructions}

Before starting the curriculum appraisal process, a HECAT coordinator was identified. A HECAT committee was formed, and the roles and responsibilities of each member were

\section{Table I National Health Education Standards ${ }^{\mathrm{a}}$}

Standard I: Students will comprehend concepts related to health promotion and disease prevention to enhance health.

Standard 2: Students will analyze the influence of family, peers, culture, media, technology, and other factors on health behaviors.

Standard 3: Students will demonstrate the ability to access valid information and products and services to enhance health.

Standard 4: Students will demonstrate the ability to use interpersonal communication skills to enhance health and avoid or reduce health risks.

Standard 5: Students will demonstrate the ability to use decision-making skills to enhance health.

Standard 6: Students will demonstrate the ability to use goal-setting skills to enhance health.

Standard 7: Students will demonstrate the ability to practice health-enhancing behaviors and avoid or reduce health risks.

Standard 8: Students will demonstrate the ability to advocate for personal, family, and community health.

Note: ${ }^{2}$ Data from Centers for Diseases Control and Prevention. Health education curriculum analysis tool (HECAT). Available from: https://www.cdc.gov/healthyyouth/HECAT/.'2 
distinguished and identified. Then, a curriculum and three modules including healthy eating, physical activity, and safety were obtained to be review and assessed. The HECAT essential items were determined, and the curriculum analysis tool for use by the reviewers was finalized. The next step was to provide an orientation and direction for team members while determining a curriculum review assignment for each member. Finally, a timeline for the review process was developed.

\section{Concept coverage scoring}

The score based on the criteria listed below addresses the curriculum:

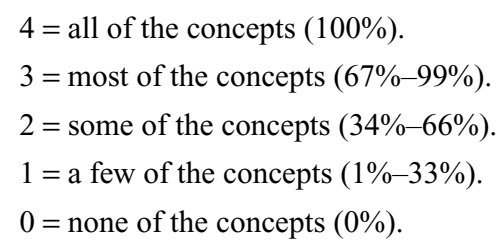

\section{Data collection procedure}

\section{Phase one}

In order to evaluate safety, physical activity, and healthy eating modules, the HECAT was translated to Persian. Three professionals in the field of health education, educational management, and English provided suggestions for improving the practicality of the translation.

\section{Phase two}

Based on the HECAT guidelines, the third-grade students' textbooks and teaching aids were assessed and evaluated in concordance to the standards and frameworks of the HECAT committee through the curriculum appraisal process. All the participants determined the percentage of covered standards. When indicating the status of the scores, each score was divided to the highest score and then multiplied by 100 . If the content was $100 \%$ covered, the curriculum had covered all the expectations of the defined knowledge and skills. If $67 \%-99 \%$ of the introduced content was covered, the curriculum had covered some of the expectations of the defined knowledge module. If $1 \%-33 \%$ of the content was covered, the curriculum had covered few of the expectations. Also, if $0 \%$ of the content was covered, the curriculum had covered few of the expectations.

\section{Phase three}

For addressing key health-related concepts, encouraging creative expression, and sharing personal thoughts, feelings, and opinions, a focus group discussion was held. The suggested solutions for improving the curriculum in the healthy diet module about standards of health education discussion were related to questions regarding improving third-grade curriculum. These questions were related to 1) skills for achieving all types of information, products, appropriate hygiene services, and comprehensive concepts for preventing diseases and enhancing health; 2) skills related to the ability to use health-boosting behaviors and prevent high-risk behaviors, skills for making use of interpersonal communications, and targeting skills for decision-making; and 3) skills related to analyzing the determinants of health such as culture, media, and technology.

Supporting skills were thoroughly guided, and also a focused group discussion session was held with the presence of 12 experts in the field of educational sciences and educational hygiene along with the health center and education staff. The duration of the group discussion session was 3 hours, and all the participants approved that the interview could be recorded. All the interviews were typed, and the recorded tape was listened to several times so that the exact statements were extracted and the accuracy of the data was certified.

\section{Ethical considerations}

This research was approved by the Research Ethics Committee of Tabriz University of Medical Sciences (Institutional Review Board: 5/4/11489-07/01/2016). We fully explained the objectives and methods of the study to the participants and obtained written informed consent.

\section{Results}

Table 2 shows the results of evaluating the third-grade curriculum for health subjects regarding physical training, science and social studies educational materials about healthy eating, safety, and physical activity modules. As can be seen, the highest mean percentage covered is $25.59 \%$ and belongs to safety and the least mean percentage covered is $12.78 \%$, which is for the healthy diet module. Thus, since the entire module's mean percentage covered is $<34 \%$, the mentioned textbooks cover minimum content regarding healthy eating, safety, and physical activity.

Table 2 Concept and skills coverage of the safety, healthy eating, and physical activity modules

\begin{tabular}{lllll}
\hline Topics & Sciences & $\begin{array}{l}\text { Physical } \\
\text { training }\end{array}$ & $\begin{array}{l}\text { Social } \\
\text { studies }\end{array}$ & Mean \\
\hline Safety & 0 & 20.96 & 55.80 & 25.59 \\
Healthy diet & 38.33 & 0 & 0 & 12.78 \\
Physical activity & 0 & 63.11 & 0 & 21.04 \\
\hline
\end{tabular}


In regard to specifying experts' suggested solutions for improving curriculum, a focused group discussion was used. The findings are summarized in Table 3.

\section{Discussion}

Like many other countries, Iran is seeing an upswing in noncommunicable diseases among school students. Studies show that obesity is the most common health problem among the youth, which provides the trigger for other illnesses such as diabetes, high blood pressure, and cardiovascular problems. In addition, challenging social and behavioral issues, such as the increasing number of drug addicts and the spread of HIV, all have their roots in the lack of awareness among the young generation. ${ }^{14}$

Applying the HECAT, the third-grade curriculum was assessed in accordance with health-related items. The highest mean percentage covered was $59.25 \%$, which belonged to the safety module, and the least mean percentage covered was for the healthy eating module. Since all the modules had a percentage covered $<34 \%$, only a few of the expected contents were covered.

Most of the studies done in this field assessed health or other fields and were not similar to our study. ${ }^{6}$ The majority of scholars revealed an infinite spectrum of a positive effect of school-based interventions at the beginning of childhood on health in adulthood. ${ }^{11,15}$ Furthermore, Priya et $\mathrm{al}^{9}$ analyzed the content of textbooks in Tamil Nadu, India. Majority of students had an adequate level of knowledge on oral health but a low level of oral health practices at all educational levels. Also, they observed that the content presented in textbooks needed periodic revisions and that the methods of health education must be strengthened.

Moreover, the results from analyzing the content of 474 school books of two educational levels in countries such as Laos, Cambodia, Nepal, Bangladesh, Sri Lanka, Zambia, Nigeria, Benin, and Ghana showed that just 35 books had information about malaria. ${ }^{16}$ The results also indicated that the books rarely had essential knowledge and skills to prevent the regional people from contracting major health problems. Furthermore, a systematic review evaluated the content of textbooks in schools. After screening the eligible studies according to inclusion/exclusion criteria, nine school works were investigated from the United States and Spain. Results showed that the quality of content was not suitable and needed improvement. Also, some textbooks had unsuitable content or the health information was inaccurate. ${ }^{11}$

The members of the HECAT committee are addressing skill-based standards such as goal setting and decision-making, but curricula must be continually reviewed and revised to reflect emerging concepts like advocacy. According to the results of the present study, it is blatant that limited attention has been given to health education. Nevertheless, we expected that at least a few of the aspects of health in elementary textbooks would be considered and students would be familiar with health-centered education, its features, and difficulties. Thus, based on the abovementioned studies, we can conclude that since the content of elementary textbooks is an important tool to help identify and educate regarding hygiene behaviors among students, it is essential that experts consider codifying the objectives of education in designing elementary textbooks. ${ }^{17}$

Table 3 The proposed solutions for the promoting healthy eating module

\begin{tabular}{|c|c|}
\hline Theme & Subthemes \\
\hline $\begin{array}{l}\text { Acknowledging and identifying nutritional } \\
\text { action and behaviors }\end{array}$ & $\begin{array}{l}\text { Teaching students about the characteristics of healthy food and their variety, identifying different } \\
\text { food groups using simple and familiar contents for students, enhancing student's knowledge regarding } \\
\text { calorie, information on fruits and vegetables, explaining about a balanced diet (fatty food, sweets, salt) } \\
\text { and diseases related to nutrition, teaching the features of an unhealthy diet, acknowledging functional } \\
\text { activities for eating healthy foods, paying attention to children's needs and interests regarding educating } \\
\text { on healthy diet based on recent methods, reconsidering the content and subject (images) of textbooks } \\
\text { and using expert and well-educated teachers in matters of health, and familiarizing students with } \\
\text { alternative food sources in food groups }\end{array}$ \\
\hline $\begin{array}{l}\text { Educating life skills and adopting healthy } \\
\text { diet behaviors }\end{array}$ & $\begin{array}{l}\text { Enabling students in describing and explaining the effect of unhealthy foods (fatty food, sweets, salt), } \\
\text { helping students have commitment to using healthy food, questioning students and interacting with } \\
\text { them for improving dietary choices and healthy eating, educating students to say no to unhealthy foods, } \\
\text { choosing health helpers and health ambassador among students, enhancing student's self-confidence and } \\
\text { decision-making ability, and enabling and allowing students to be implemented in various school settings } \\
\text { and communities in relation to healthy foods }\end{array}$ \\
\hline $\begin{array}{l}\text { Making use of the effect of social norms } \\
\text { for adopting healthy dietary patterns }\end{array}$ & $\begin{array}{l}\text { Motivating students to consume healthy and homemade food, imposing peer education to choice and } \\
\text { control over students' intake and use of healthy foods, enhancing knowledge regarding the effect of } \\
\text { social networks on food choices, food pattern, and choosing healthy food, and using methods such as } \\
\text { playing, storytelling, and modern methods for educating students regarding healthy eating }\end{array}$ \\
\hline
\end{tabular}




\section{Conclusion and implications}

The HECAT contains guidance, appraisal tools, and resources for carrying out a clear, complete, and consistent examination of health education curricula. With regard to health promotion approaches, some schoolbooks have not paid enough attention to what ought to be our highest priority among children. In general, although health education plays a crucial role in the development of healthy, inclusive, and equitable social, psychological, and physical environment, we can conclude that some of the health topics in the curriculum were not satisfactory considered.

By assessing the content of the schoolbooks, we can provide strengths and weaknesses to the policymakers and key managers along with the goals set for possible modification of the contents. Furthermore, many of the messages in the textbooks are not based on scientific evidence. Therefore, standards are needed to facilitate the production of effective school curricula for children's health promotion.

School is one of the best platforms to educate the youth about diseases and their prevention, but health education does not appear to be a priority in the school curriculum, and subjects dealing with the issues are not given serious thought. The Ministry of Education is in charge of educational planning, financing, administration, curriculum, and textbook development. Health chapters are introduced in biology and hygiene books, but are optional and taught, if at all, outside of the formal class hours. ${ }^{14}$ As a compulsory subject at the primary schools, they have to get the approval of the Supreme Council of Education, the body that decides all education-related policies and regulations. The Health Ministry should also propose a comprehensive health education program based on which textbook content would include chapters on health and risky behaviors in all grades.

\section{Acknowledgments}

This study was supported by the Tabriz University of Medical Sciences (grant number 5/53/7172-20/01/2016). We appreciate the deputy of research and technology for their valuable support. We are also most grateful for the assistance given by the facilitators and participants.

\section{Author contributions}

All authors confirm that they have participated sufficiently in the work to take public responsibility for the content, including participation in the concept, design, analysis, writing, and revision of the manuscript.

\section{Disclosure}

The authors report no conflicts of interest in this work.

\section{References}

1. WHO. The Ottawa Charter for Health Promotion. Available from: http://www.who.int/healthpromotion/conferences/previous/ottawa/en/. Accessed February 14, 2016.

2. WHO. What Is a Health Promoting School? Available from: http:// www.who.int/school_youth_health/gshi/hps/en/. Accessed December $14,2016$.

3. Atkins MC, Hoagwood KE, Seidman E. Toward the integration of education and mental health in schools. Admin Policy Ment Health Ment Health Services Res. 2010;37(1-2):40-47.

4. Bundy D. School health and nutrition: policy and programs. Food Nutr Bull. 2005;26(2):186-192.

5. Vermont Department of Education Safe and Healthy Schools Team. Vermont Health Education Guidelines for Curriculum and Assessment. 2nd ed. 2010. Available from: http://healthandlearning.org/curriculumdevelopment/. Accessed November 18, 2015.

6. Kazemian R, Ghasemi H, Movahhed T, Kazemian A. Health education in primary school textbooks in Iran. J Dent. 2014;11(5):536-544

7. Taik LM. Analysis on the obesity-related content in governmentapproved textbooks for physical education of fourth graders in elementary schools based on textbooks following the 2009 curriculum revision. Edu Res. 2014;59:89-118.

8. Sliepcevich EM. School health education: appraisal of a conceptual approach to curriculum development. J School Health. 2001;71(8):417-421.

9. Priya G, Asokan S, Kandaswamy D, Malliga S, Arthi G. Health camps in schools and content analysis of the school textbooks: a cross-sectional study in Tamil Nadu. J Indian Soc Pedod Prev Dent. 2016;34(3): $223-226$.

10. O'Dea JA. School-based health education strategies for the improvement of body image and prevention of eating problems: an overview of safe and successful interventions. Health Edu. 2005;105(1):11-33.

11. Nomoto M, Nonaka D, Mizoue T, Kobayashi J, Jimba M. Content analysis of school textbooks on health topics: a systematic review. Biosci Trends. 2011;5(2):61-68.

12. Centers for Diseases Control and Prevention. Health education curriculum analysis tool (HECAT). Available from: https://www.cdc.gov/ healthyyouth/HECAT/. Accessed March 1, 2018.

13. Hidde S. Sexual Health Education Curriculum Review 2011 Joint Report. Available from: http://www.k12.wa.us/HIVSexualhealth/ pubdocs/2011SHECurriculumReview.pdf. Accessed March 1, 2018

14. Financial Tribune Daily. School Textbooks Miss Key Health Education. Available from: http://goo.gl/2dEi0O. Accessed March 1, 2018.

15. Reynolds AJ, Temple JA, Ou S, et al. Effects of a school-based, early childhood intervention on adult health and well-being: a 19-year follow-up of low-income families. Arch Pediatr Adolesc Med. 2007;161(8):730-739.

16. Nonaka D, Jimba M, Mizoue T, et al. Content analysis of primary and secondary school textbooks regarding malaria control: a multi-country study. PLoS One. 2012;7(5):e36629.

17. Nyberg G, Sundblom E, Norman Å, Elinder LS. A healthy school startparental support to promote healthy dietary habits and physical activity in children: design and evaluation of a cluster-randomized intervention. BMC Public Health. 2011;11(1):185. 
The Journal of Multidisciplinary Healthcare is an international, peerreviewed open-access journal that aims to represent and publish research in healthcare areas delivered by practitioners of different disciplines. This includes studies and reviews conducted by multidisciplinary teams as well as research which evaluates the results or conduct of such teams or health care processes in general. The journal covers a very wide range of areas and welcomes submissions from practitioners at all levels, from all over the world. The manuscript management system is completely online and includes a very quick and fair peer-review system. Visit http://www.dovepress.com/ testimonials.php to read real quotes from published authors. 